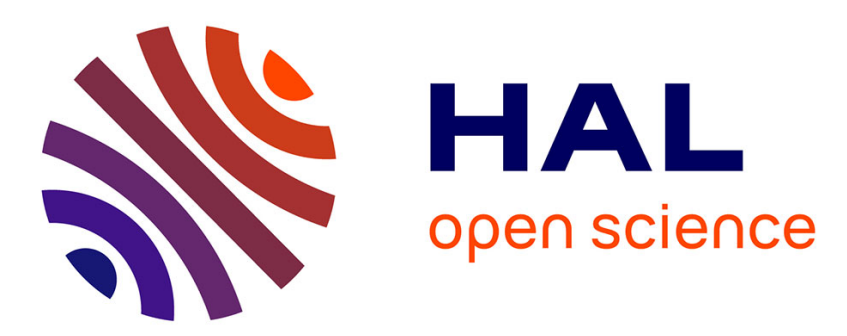

\title{
Beware of the gorilla: Effect of goal priming on inattentional blindness
}

Jean-Baptiste Légal, Peggy Chekroun, Viviane Coiffard, Fabrice Gabarrot

\section{To cite this version:}

Jean-Baptiste Légal, Peggy Chekroun, Viviane Coiffard, Fabrice Gabarrot. Beware of the gorilla: Effect of goal priming on inattentional blindness. Consciousness and Cognition, 2017, 55, pp.165-171. 10.1016/j.concog.2017.08.004 . hal-01667136

\section{HAL Id: hal-01667136 https://u-bourgogne.hal.science/hal-01667136}

Submitted on 10 Jan 2019

HAL is a multi-disciplinary open access archive for the deposit and dissemination of scientific research documents, whether they are published or not. The documents may come from teaching and research institutions in France or abroad, or from public or private research centers.
L'archive ouverte pluridisciplinaire HAL, est destinée au dépôt et à la diffusion de documents scientifiques de niveau recherche, publiés ou non, émanant des établissements d'enseignement et de recherche français ou étrangers, des laboratoires publics ou privés. 


\title{
Beware of the gorilla: Effect of goal priming on inattentional blindness
}

\author{
Jean-Baptiste Légal, Peggy Chekroun, Viviane Coiffard, Fabrice \\ Gabarrot
}

\section{Introduction}

Many people have experienced a time when either themselves or someone else was engaged in an activity and appeared to be deaf or blind to what was happening around them. This phenomenon, when it affects the visual channel, is known as "inattentional blindness". Even if focusing attention on a single activity is generally an adaptive process, it can lead to problems if attention is required to process an unexpected event or to rapidly adapt to the ongoing situation. For instance, drivers involved in a car accident frequently claim that they "looked but failed" to see the other vehicle (White, 2006). This paper explores one potential method to improve the detection of an unexpected event in an inattentional blindness paradigm: goal priming.

\subsection{Inattentional blindness}

Inattentional blindness (Mack \& Rock, 1998) refers to the fact that salient objects or events fail to reach awareness when attention is otherwise engaged in a task. In 1999, Simons and Chabris provided a striking example of this phenomenon: while watching a short video clip, almost half of the participants who had been instructed to count the number of passes performed by basketball players failed to notice a person wearing a gorilla suit, even if the gorilla was fully visible for an extended time.

Two factors are particularly important in the occurrence of inattentional blindness: the unexpected event's features and the demands of the primary task (Most, Scholl, Clifford, \& Simons, 2005; Simons \& Jensen, 2009). Observers are more likely to detect an unexpected event that shares visual features (e.g., color, shape) with the targeted events. For instance, in the gorilla example, detection rates were higher when observers had to monitor players wearing black shirts (i.e., sharing the same color as the gorilla). 
Inattentional blindness also depends on the difficulty of the monitoring task. The more difficult the task, such as requiring a high level of attention, the less often the observers detect the unexpected event. In other words, inattentional blindness depends on the unexpected target's characteristics and on the goal's demands.

\subsection{Goal priming}

If goal pursuit is usually considered as a voluntary and consciously controlled activity, it can also occur outside of awareness, intent, and control (Bargh, Gollwitzer, Lee-Chai, Barndollar, \& Troetschel, 2001; Bargh, Schwader, Hailey, Dyer, \& Boothby, 2012). Indeed, if goals are generally set in a volitional way, they can also be activated and pursued nonconsciously, leading to outcomes comparable to conscious goal setting and pursuit (Bargh et al., 2001; Chartrand \& Bargh, 1996). In terms of processes, Hassin, Bargh, Engell, and McCulluch (2009) suggested that once a goal is primed, it enters implicit working memory (IWM) and some capacity such as mental resources, or processing time, is allocated to this goal. Then, if the goal is allocated sufficient capacity, schemas, means and relevant knowledge are selected or created. Finally, nonconscious goal pursuit is triggered and influences behavior (e.g., Dijksterhuis, Chartrand, \& Aarts, 2007) as well as information processing (e.g., Dijksterhuis \& Aarts, 2010; Mitchell, Macrae, Schooler, Rowe, \& Milne, 2002). Interestingly, it was demonstrated that nonconscious goal pursuit is flexible (Hassin, Aarts, Eitam, Custers, \& Kleiman, 2009) and can run in parallel to a conscious activity. Thus, conscious and nonconscious goals can coexist, especially when both types of goals are compatible or share a high degree of similarity (e.g., Bargh et al., 2001; Hassin, Aarts et al., 2009; Hassin, Bargh et al., 2009; Légal \& Meyer, 2009). In that case, nonconscious and conscious goal pursuits would make use of the same underlying motivational circuits and systems (Huang \& Bargh, 2014) and lead to improved performance.

\subsection{Current study}

Inattentional blindness relies on the allocation of an observer's attentional resources and, as a consequence, is closely related to the processing of goals. During a task or an activity, a conscious goal defines what to observe and what is important. In other words, the goal linked to the primary task or activity sets up a prioritization of the scope of attention and determines the allocation of attentional resources, creating what is called an attentional set (Most et al., 2005). In line with research about implicit working memory (Hassin, Aarts et al., 2009; Hassin, Bargh et al., 2009), we propose that goal priming could be a way to nonconsciously allocate unused attentional resources to a task. Specifically, goal priming could be a way to allow the involvement of attentional resources with aspects other than those related to the primary task objectives.

In this article, we explore whether goal priming can improve rates of noticing an unexpected event in an inattentional blindness framework. To that end, we combined two classical paradigms. The first one, from the goal priming literature, allowed us to prime either a nonconscious detection goal, no goal, or the word "gorilla" (i.e., the upcoming unexpected event) in participants. The second paradigm refers to Simons and Chabris' (1999) "gorilla experiment" on inattentional blindness. In this paradigm, participants engage in a monitoring task involving basketball players and frequently miss the unexpected arrival of a gorilla on the playground.

Because of its motivational features, we assume that priming a detection goal, compared to the no goal and the gorilla-prime conditions, should improve the detection of the unexpected event in the subsequent monitoring task. In contrast, priming the name of the target to detect, as it is not linked to motivational processes, should not affect the allocation of attentional resources, and therefore should not influence detection rates (Kreitz, Schnuerch, Furley, Gibbons, \& Memmert, 2014). We also assume that the goal priming effect should be more likely to occur when a part of the attentional resource remains available despite the task performance. In other words, the goal priming effect should occur more often for an easy monitoring task rather than a hard one, this latter consuming more resources. Finally, since our detection goal is compatible with and applicable to the monitoring task, it should also lead to a better performance on this task. Indeed, priming of goals applicable in a task should result in the investment of more resources and lead to better performance.

\section{Material and method}

\subsection{Participants and design}

One hundred and sixty-seven first-year psychology students participated in the study in exchange for course credits. Participants were randomly assigned to one of the conditions of a 3 (priming: detection-prime, gorilla-prime, no-prime) $\times 2$ (monitoring task difficulty: normal vs. high) between-subjects design. Data from 14 participants were discarded either because they reported losing count of the passes $(n=6)$ or because the participant already knew about the video $(n=8)$.

\subsection{Materials and procedure}

Participants were told they would participate in two unrelated studies. The first study, presented as a decision task, was a cover for our subliminal priming manipulation. The second study, presented as a monitoring task, allowed us to assess inattentional blindness. After the completion of the two studies, participants were thanked and debriefed.

\subsubsection{Decision task/priming manipulation}

Upon arriving to the lab for the studies, participants were invited to start with a "decision task" in which they were instructed to 
press the "Q" key when a circle appeared on the screen and the "M" key when a cross appeared. Under the cover of this task, we used a subliminal priming procedure to activate a specific content in participants' memory. For each trial, the sequence was the following:(a) fixation point $(380 \mathrm{~ms})$; (b) target (cross or circle; $120 \mathrm{~ms}$ ); (c) prime or no prime (22 ms); (d) post-mask (until response). After 10 practice trials, participants completed 30 test trials in which a prime followed the target. In the detection-prime condition, primes were verbs associated with a detection goal. Based on a pilot study in which we asked 35 students to write down the verbs they spontaneously associated to the goal of detecting something, we used the 10 following verbs: to detect, to remark, to identify, to discover, to see, to spot, to perceive, to locate, to distinguish, and to notice. We selected these verbs because they were cited by more than $80 \%$ of the participants, indicating a strong association with the goal we intended to prime. Each of the 10 verbs was primed randomly for a total of 3 times. In the gorilla-prime condition, verbs were replaced by the word gorilla. Finally, in the no-prime condition, participants performed the task but no words were flashed.

In order to check for participants' awareness of the primes, we conducted a subliminal-check test on a different sample of 15 participants. In this test, we presented the same material as the one used in the main experiment (i.e., all the words used as primes) but with a different instruction. While they had to detect whether a cross or a circle appeared on the screen in the main experiment, they were there informed that words would be flashed very quickly and asked to read/guess these words and write them down on an answer sheet. On the total number of trials, participants only correctly reported the primed word 2 times. One participant once succeeded in reporting the verb "to notice" and another participant once reported the word "detection" instead of "to detect"1,2. So, participants were able to accurately report the displayed word in only $0.3 \%$ of the cases, suggesting that people were unable to identify the words at such a brief presentation.

\subsubsection{Monitoring task}

Once the decision task was over, participants proceeded to the monitoring task. Procedure and materials for this section were adapted from Simons and Chabris (1999). Specifically, we used Simons and Chabris' gorilla video. ${ }^{3}$ In this sequence involving two teams of players passing basketballs, a person in a gorilla suit unexpectedly arrived from the right of the screen, stopped in the middle of the basketball players, faced the camera, thumped his chest, and then resumed his walk across the screen. To make the gorilla harder to detect, we asked participants to monitor the passes made by players wearing white shirts (no color sharing with the gorilla). Difficulty of the task was also manipulated through instructions. In the normal monitoring condition, participants were asked to mentally count the total number of passes made by the White team. In the high difficulty condition, they had to count both the total number of passes and the number of aerial passes. Dependent measures were the count(s) of passes and detection (or not) of the unexpected event.

At the end of the video, following Simons and Chabris' procedure, participants wrote down their count(s) and answered the following questions: While you were counting, did you notice anything unusual? Did you notice anything other than the basketball players? Did you see anyone else (beside the players)? Did you see a gorilla walking through the screen? After any Yes response, participants were asked to precisely indicate what they noticed. Participants were also asked whether they knew the video or watched it before.

\subsubsection{Awareness check}

In the final section of the questionnaire, we probed our nonconscious priming manipulation using a funneled questionnaire (Bargh \& Chartrand, 2000). Specifically, we asked participants to indicate (1) if they noticed something strange in the detection task and (2) if they thought what they did in the detection task could have affected what they their performance in the monitoring task. For any Yes answer to these questions, participants had to explain precisely the reasons of their response. This allowed us to check that participants had not perceive the subliminal primes and did not discover the relation between the two studies.

\section{Results}

\subsection{Awareness check}

None of the participants reported having seen words during the task nor were able to recall any of the primed words. Moreover, no participants indicated any awareness or suspicion that the detection task was related to the monitoring task and could have influence their performance in any way.

\subsection{Performance}

We computed an error score for each participant, defined as the deviation of their reported count from the actual total number of passes. Priming was contrast coded. The first contrast code for priming compared the detection-prime condition (coded +2 ) against the gorilla-prime (coded -1 ) and the no-prime condition (coded -1 ) together. The second contrast code compared the gorilla-prime condition (coded +1 ) to the no-prime condition (coded -1 ). The detection-prime condition was coded 0 . Task difficulty was also

\footnotetext{
${ }^{1}$ Infinitive verbs are single words in French.

${ }^{2}$ As the words are very close (respectively "détection" and "détecter" in French) we considered it as a correct answer.

${ }^{3}$ For a link to the gorilla video, see: www.theinvisiblegorilla.com.
} 
contrast coded, with normal difficulty coded -1 and high difficulty coded +1 .

\subsubsection{Unexpected event detection}

Following Simons and Chabris (1999), we considered that participants detected the unexpected event if: (1) at any point they clearly reported having seen a gorilla or a person wearing a gorilla suit and (2) if answers to the four questions used to determine whether they had noticed the unexpected event were consistent. Unexpected event detection was analyzed using a binary logistic regression analysis. Detection was regressed on the two priming codes, difficulty and the interaction between the two codes and difficulty. Analyses revealed that, overall, only $40.4 \%$ of the participants reported having seen the gorilla. Regression analyses also revealed an overall main effect of task difficulty, Wald $\chi^{2}(1)=27.73, p<0.001$. Detection rates were higher in the normal con-dition (63.9\%) compared to the high difficulty condition (19,0\%). Participants more readily detected the unexpected event when they had to process one rather than two counts of passes.

We assumed that goal priming would affect detection rates. In particular, we expected that participants primed with a detection goal would be more likely to detect the gorilla compared to participants in the other conditions. A significant effect of our first contrast coding for priming conditions was found, Wald $\chi^{2}(1)=3.88, p=0.049$. Participants in the detection-prime condition (53.70\%) detected the gorilla significantly more often compared to the gorilla-prime (30.51\%) and the no-prime conditions (40.00\%). Detection rates in the gorilla-prime and the no-prime conditions did not differ from each other, ald $^{2}(1)=0.948, p=0.33$.

Our second assumption was that the goal priming effect on detection should vary as a function of the level of available attentional resources. In other words, we assumed an interaction between goal priming and the difficulty of the task. Results yielded a significant interaction between difficulty and our first contrast (i.e., detection-prime vs. gorilla-prime and no-prime conditions), Wald $\chi^{2}(1)=$ $3.74, p=0.05$. At the normal level of difficulty, priming participants with a detection goal significantly increased the detection rate $(82.14 \%)$ compared to the gorilla-prime condition $(53.85 \%)$, Wald $\chi^{2}(1)=4.72, p=0.03$, and the no-prime condition (50.00\%), Wald $\chi^{2}(1)=5.00, \mathrm{p}=0.025$. The gorilla-prime and the no-prime conditions did not differ from each other, Wald $\chi^{2}(1)=0.063, p=$ 0.80 . When difficulty was high, the detection rate in the detection-prime condition differed neither from the gorilla-prime condition, Wald $\chi^{2}(1)=1.20, p=0.27$, nor from the no-prime condition, Wald $\chi^{2}(1)=0.458, p=0.50$. Fig. 1 depicts the percentage of participants detecting the gorilla in each condition.

\subsubsection{Monitoring task performance}

Error score was regressed on the two priming codes, difficulty and the interaction between the two codes and difficulty. The analysis revealed a main effect of task difficulty, $B=2.33, p<0.001$. As expected, the mean error was higher in the high difficulty condition $(M=5.98, S D=6.24)$ compared to the normal condition $(M=1.33, S D=1.87)$. Furthermore, the analysis revealed a marginal effect of our first contrast coding for priming conditions, $B=-0.495, p=0.066$. The mean error in the detection-prime condition $(M=2.61, S D=4.10)$ was lower compared to the gorilla-prime and the no-prime conditions $(M=4.37, S D=5.75$ and $M$ $=4.52, S D=5.70$, respectively). The last two conditions did not differ from each other, $B=-0.068, p=0.89$. The analysis revealed neither an interaction between difficulty and our first contrast (i.e., detection-prime vs. gorilla-prime and no-prime con-ditions), $B=$ $-0.37, p=0.172$, nor an interaction between difficulty and our second contrast (i.e., gorilla-prime vs. no-prime conditions), $B=$ $-0.303, p=0.53$. The results are summarized in Fig. 2 .

\section{Discussion}

This study explored whether the priming of a detection goal could improve noticing rates for an unexpected event in a classical inattentional blindness paradigm. Along with the assumption that nonconscious goal pursuit is flexible and can recruit resources through implicit working memory, we hypothesized that goal priming could improve detection of an unexpected event, especially when the monitoring task is not too demanding in terms of attentional resources. The results support these expectations. In the absence of priming, noticing rates are consistent with previous research (Simons \& Chabris, 1999), indicating that a large number of

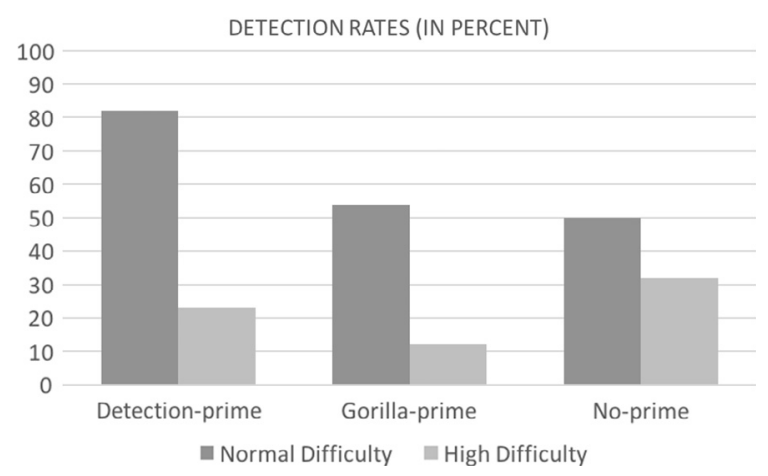

Fig. 1. Detection rates as a function of task difficulty and priming condition. 


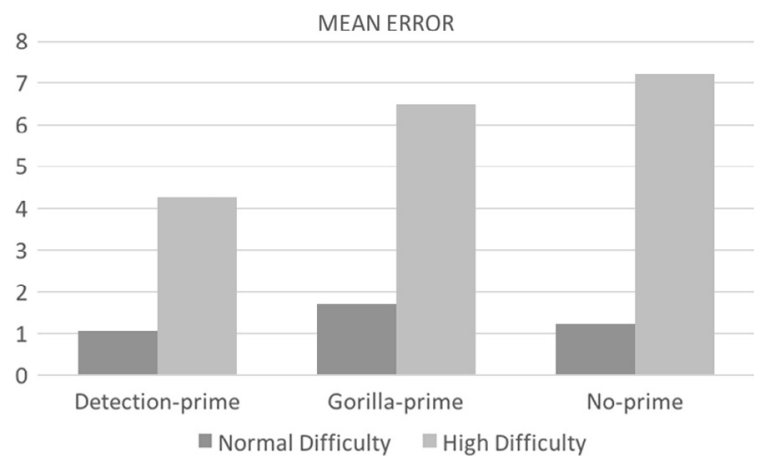

Fig. 2. Error rates as a function of task difficulty and priming condition.

persons failed to notice the unexpected event and that inattentional blindness occurs more frequently when the monitoring task is difficult. Interestingly, the results also indicate that goal priming can significantly improve the detection of an unexpected event when the monitoring task is not too difficult (i.e., requires a moderate amount of attentional resources).

It also appears that the semantic pre-activation of the unexpected target (i.e., the word gorilla) in memory, because of its lack of motivational features, does not influence attention management. This result is in line with the work of Kreitz et al. (2014), who repeatedly found that the pre-activation of the target to detect had no effect on inattentional blindness. Moreover, this motivational explanation is congruent with the results of Rattan and Eberhardt (2010), who found that giving a social meaning and motivational features to the target to detect can direct our visual system towards associated visual information that was otherwise overlooked.

In terms of underlying processes, we propose two possible interpretations of our results. First, results can be interpreted in terms of motivation and interplay between nonconscious and conscious goals pursuit. Indeed, at a goal level, the primed goal led to higher rates of detection when the task did not imply the pursuit of multiple conscious goals. When participants pursued the conscious monitoring goal and the nonconscious detection goal, priming had a positive effect on detection. Such positive effects of the interplay of compatible conscious and nonconscious goals on performance were previously obtained and can be explained by the motivational processes triggered by the priming manipulation (e.g., Bargh et al., 2001; Hassin, Aarts et al., 2009; Hassin, Bargh et al., 2009; Légal \& Meyer, 2009). It can also explain why the detection goal priming improved performance in the monitoring task as well as the detection of the unexpected event. In sum, when the difficulty of the monitoring task was moderate, priming the detection goal subsequently made participants better at detecting anything. In contrast, when people had two conscious goals in mind (i.e., keeping two separate running counts) along with the nonconscious detection goal, the positive effect of priming disappeared. One can assume that, in the case of multiple conscious goals (or a complex conscious goal), less resources are available, leaving less room for the priming effect to occur (Légal, Chappé, Coiffard, \& Villard-Forest, 2012). The underlying processes of the effect of interrelated nonconscious and conscious goals still need to be further disentangled and the relation between the goals (compatibility, strength of the relation, importance or personal relevance of the conscious goal, etc.) could constitute a key factor in their understanding.

Alternatively, results can be interpreted in terms of the functioning of the attentional system and attention regulation. In his perceptual cycle framework, Neisser (1976) suggested that preconsciously processed information might guide attention. Experimental evidence of such kind of processes have since been provided. For instance, Folk and Remington (2008) demonstrated that priming a specific feature (e.g., color) can nonconsciously direct visual attention in a subsequent task. Davies, Waterman, White, and Davies (2013) also demonstrated that observers can nonconsciously develop an attentional set for a property not specified in the task instructions. Here, we propose that goal priming could create a nonconscious attentional setting in implicit working memory, allowing the use of remaining attentional resources. As in the case of a conscious goal, the nonconscious attentional setting could help in differentiating goal-relevant from goal-irrelevant cues and, globally, increase cognitive flexibility. If it unlikely defines critical dimensions of information selection in a very specific way, it could drive or cue attention or guide to a global rather than a local processing of information. Specifically, a nonconscious attentional setting could produce expectations and a state of increased attentional readiness that would subsequently allow for a better detection of unexpected events and promote attentional shifts. This interpretation is in line with Bressan and Pizzighello (2008), who suggested that expectations create a state of alertness that can generate an attentional shift, even when attentional resources are consumed by another task. Thus, a portion of the attentional resources would remain allocated to (un)expected stimuli. If an attentional set primarily influences sustained attention, a nonconscious attentional setting would influence preconscious processing of information, transient attention, and possibly the shift from transient to sustained attention. Finally, this explanation would also be consistent with the fact that implicit and explicit attention sets appear to be dissociated (Most et al., 2005).

More globally, our findings are also in line with results of Marien, Custers, Hassin, and Aarts (2012) who demonstrated that nonconscious goal priming (1) can hijack executive function, impacting subsequent performance and (2) that the recruitment of executive control by primed goals is not accompanied by conscious awareness of the goal or other goal-related experiences (e.g., perceived effort). 


\section{Limitations}

A first limitation of our study may concern the subliminality of the primes. The question of how to optimally measure awareness in experiments on nonconscious processing has been a long-standing one, and the issue is still much debated (Rothkirch \& Hesselmann, 2017). The data of the subliminality-check test as well as the participants' answer to the funneled-de-briefing questionnaire indicate that people were not able to detect the primed words. So, it is unlikely that participants had a conscious detection goal in mind while performing the monitoring task. Nevertheless, given the measures used in the main study, we cannot be completely sure that some of the participants have not been able to consciously process one or more of our primes. In future research, other procedures than visual masking (such as a Continuous Flash Suppression task; e.g., Tsuchiya \& Koch, 2005) could be considered to more thoroughly exclude the involvement of awareness or partial awareness. Though, it is important to note that subliminality of the primes was not our main concern in designing the study. Indeed, the core principle in our research relies more on the lack of awareness of the influence of the primes rather than on the lack of awareness of the primes themselves (Bargh, 1992; Doyen, Klein, Simons, \& Cleeremans, 2014; Hassin, 2013).

The underlying process concerning our priming effect will also need more refinements. Based on the seminal goal priming literature (Bargh et al., 2001), we assumed that our priming manipulation triggered a nonconscious detection goal in participants. Though, one could argue that our priming procedure activated a mindset or a set of procedures rather than a goal. Even if criteria have been proposed (e.g., Förster, Liberman, \& Friedman, 2007), distinguishing goal-priming from other types of priming still re-mains an issue of debate. Adding motivational measures will be a way to improve our paradigm on this point.

\section{Conclusions}

During our daily activities, we receive a large amount of visual information. However, due to capacity limitations, only a part of the stimuli we receive are consciously perceived and processed. Our cognitive system cope with these capacity constraints by consciously or nonconsciously- guiding sensory processing and attention towards the stimuli that are most important regarding to our current goal(s). Researchers developed and used techniques to dissociate visual input from awareness (e.g., backward masking, binocular rivalry, continuous flash suppression, visual crowding; Faivre, Berthet, \& Kouider, 2014) and the understanding the mechanisms of visual (un)awareness as well as the division of labor between conscious and nonconscious processes attracted considerable research effort (Hassin, 2013; Hedger, Gray, Garner, \& Adams, 2016).

While emergence into consciousness is traditionally addressed in rivalry paradigms or continuous flash suppression (e.g., Hedger et al., 2016; Ooi \& He, 1999), we chose to take a different path to explore how nonconscious processes could drive attention and help detecting an unexpected event. In this article, we bridge two distinct lines of research: inattentional blindness and nonconscious goal pursuit. To the best of our knowledge, the insights from the one have never been applied to the other. The results underscore the role of nonconscious processes in capturing attention and detection of unexpected events, indicating that a primed goal can increase detection rates. It also extends the existing evidence about the effects of goal priming on attentional processes and their regulation. In particular, nonconscious goal pursuit may influence the way in which attentional resources are allocated, recruited, or freed. However, further evidence is needed to thoroughly identify the underlying processes in terms of attentional setting and/or motivational processes.

Beyond providing supplementary data regarding the interplay between nonconscious and conscious goals, our research opens new perspectives in the understanding of how and why attention becomes sustained following the detection of an unexpected event. In the case of attention switching, models suppose complex interactions between top-down and bottom-up processes. It is assumed that topdown expectations could affect performance through setting a default level of attention. Goal priming procedures could be a way to investigate these top-down expectations and their interactions with stimulus properties. As visual working memory is used to retain relevant visual information for imminent goal-directed behavior (Gayet, Paffen, \& van der Stigchel, 2013), relations between goal priming, implicit working memory and visual working memory could also provide new understandings about the way information is selected and prioritized. Finally, from an applied perspective, these first results could serve as a basis for the development of onboard devices or methods for reducing attentional blindness.

\section{Declaration of conflict of interest}

The author(s) declared no potential conflicts of interests with respect to the authorship and/or publication of this article.

\section{Financial disclosure/funding}

The author(s) received no financial support for the research and/or authorship of this article.

\section{References}

Bargh, J. A. (1992). Does subliminality matter to social psychology? Awareness of the stimulus versus awareness of its influence. In R. F. Bornstein, \& T. S. Pittman (Eds.). Perception without awareness: Cognitive, clinical, and social perspectives (pp. 236-255). New York: Guilford Press.

Bargh, J. A., \& Chartrand, T. L. (2000). The mind in the middle. In H. Reis, \& C. Judd (Eds.). Handbook of research methods in social and personality psychology (pp. 253285). New York: Cambridge University Press. 
Bargh, J. A., Gollwitzer, P. M., Lee-Chai, A., Barndollar, K., \& Troetschel, R. (2001). The automated will: Nonconscious activation and pursuit of behavioral goals. Journal of Personality and Social Psychology, 81, 1014-1027.

Bargh, J. A., Schwader, K. L., Hailey, S. E., Dyer, R. L., \& Boothby, E. J. (2012). Automaticity in social-cognitive processes. Trends in Cognitive Science, 16, 593-605. Bressan, P., \& Pizzighello, S. (2008). The attentional cost of inattentional blindness. Cognition, 106, 370-383.

Chartrand, T. L., \& Bargh, J. A. (1996). Automatic activation of impression formation and memorization goals: Nonconcious goal priming reproduces effects of explicit task instructions. Journal of Personality and Social Psychology, 71, 464-478.

Davies, A. M. A., Waterman, S., White, R. C., \& Davies, M. (2013). When you fail to see what you were told to look for: Inattentional blindness and task instructions. Consciousness and Cognition, 22(1), 221-230.

Dijksterhuis, A., \& Aarts, H. (2010). Goals, attention, and (Un) consciousness. Annual Review of Psychology, 61, 467-490.

Dijksterhuis, A., Chartrand, T., \& Aarts, H. (2007). Effects of priming and perception on social behavior and goal pursuit. In J. Bargh (Ed.). Social psychology and the unconscious: The automaticity of higher mental processes (pp. 51-132). New York: Psychology Press.

Doyen, S., Klein, O., Simons, D. J., \& Cleeremans, A. (2014). On the other side of the mirror: Priming in cognitive and social psychology. Social Cognition, 32, 12-32.

Faivre, N., Berthet, V., \& Kouider, S. (2014). Sustained invisibility through crowding and continuous flash suppression: a comparative review. Frontiers in Psychology, 5 , 475.

Folk, C. L., \& Remington, R. W. (2008). Bottom-up priming of top-down attentional control settings. Visual Cognition, 16, 215-231.

Förster, J., Liberman, N., \& Friedman, R. S. (2007). Seven principles of goal activation: A systematic approach to distinguishing goal priming from priming of non-goal constructs. Personality and Social Psychology Review, 11(3), 211-233.

Gayet, S., Paffen, C. L. E., \& van der Stigchel, S. (2013). Information matching the content of visual working memory is prioritized for conscious access. Psychological Science, 24(12), 2472-2480.

Hassin, R. R. (2013). Yes it can: On the functional abilities of the human unconscious. Perspectives on Psychological Science, 8, $195-207$.

Hassin, R. R., Aarts, H., Eitam, B., Custers, R., \& Kleiman, T. (2009). Non-conscious goal pursuit and the effortful control of behavior. In E. Morsella, J. A. Bargh, \& P. M. Gollwitzer (Eds.). Oxford handbook of the psychology of action (pp. 549-568). New York, NY: Oxford University Press.

Hassin, R. R., Bargh, J. A., Engell, A. D., \& McCulluch, K. C. (2009). Implicit working memory. Consciousness and Cognition, 18, 665-678.

Hedger, N., Gray, K. L. H., Garner, M., \& Adams, W. J. (2016). Are visual threats prioritized without awareness? A critical review and meta analysis involving 3 behavioral paradigms and 2696 observers. Psychological Bulletin, 142, 934-968.

Huang, J. Y., \& Bargh, J. A. (2014). The selfish goal: Autonomously operating motivational structures as the proximate cause of human judgment and behavior. Behavioral and Brain Sciences, 37, 121-175.

Kreitz, C., Schnuerch, R., Furley, P. A., Gibbons, A., \& Memmert, D. (2014). Does semantic preactivation reduce inattentional blindness? Attention, Perception, \& Psychophysics, 76, 1-9.

Légal, J.-B., Chappé, J., Coiffard, V., \& Villard-Forest, A. (2012). Don’t you know that you want to trust me? Subliminal Goal Priming and Persuasion. Journal of Experimental Social Psychology, 48, 358-360.

Légal, J.-B., \& Meyer, T. (2009). Goal priming and self-efficacy: Independent contributions to motor performance. Perceptual and Motor Skills, 108, 383-391. Mack, A., \&

Rock, I. (1998). Inattentional blindness: Perception without attention. Visual Attention, 8, 55-76.

Marien, H., Custers, R., Hassin, R. R., \& Aarts, H. (2012). Unconscious goal activation and the hijacking of the executive function. Journal of Personality and Social Psychology, 103, 399-415.

Mitchell, J., Macrae, C., Schooler, J., Rowe, A., \& Milne, A. (2002). Directed remembering: Subliminal cues alter nonconscious memory strategies. Memory, 10, 381-388.

Most, S., Scholl, B., Clifford, E., \& Simons, D. (2005). What you see is what you set: Sustained inattentional blindness and the capture of awareness. Psychological Review, 112, 217-241.

Neisser, U. (1976). Cognition and reality. San Francisco: W. H. Freeman.

Ooi, T. L., \& He, Z. J. (1999). Binocular rivalry and visual awareness: The role of attention. Perception, 28, 551-574.

Rattan, A., \& Eberhardt, J. L. (2010). The role of social meaning in inattentional blindness: When the gorillas in our midst do not go unseen. Journal of Experimental Psychology, 46, 1085-1088.

Rothkirch, M., \& Hesselmann, G. (2017). What we talk about when we talk about unconscious processing - A plea for best practices. Frontiers in Psychology, 8, 835.

Simons, D., \& Chabris, C. (1999). Gorillas in our midst: Sustained inattentional blindness for dynamic events. Perception, 28, $1059-1074$.

Simons, D., \& Jensen, M. (2009). The effects of individual differences and task difficulty on inattentional blindness. Psychonomic Bulletin \& Review, 16, 398-403.

Tsuchiya, N., \& Koch, C. (2005). Continuous flash suppression reduces negative afterimages. Nature Neuroscience, 8, $1096-1101$.

White, M. (2006). Sorry mate, I didn't see you. A plausible scientific explanation. In Proceedings of the Australasian road safety research, policing and education conference 